\title{
THE PREREQUISITES OF PROSOCIAL BEHAVIOR IN HUMAN ONTOGENY
}

Irina M. Sozinova, M.S., Institute of Psychology, Russian Academy of Sciences, Russian Federation, E-mail: eiole@yandex.ru

Alexey A. Sozinov, Ph.D., Institute of Psychology, Russian Academy of Sciences; State Academic University of the Humanities, Russian Federation, E-mail: alesozinov@yandex.ru

Seppo J. Laukka, Ph.D., University of Oulu, Learning Research Laboratory (LearnLab), Finland,

E-mail: seppo.laukka@oulu.fi

Dr. Yuri I. Alexandrov, Institute of Psychology, Russian Academy of Sciences; Department of Psychology, National Research University Higher School of Economics; State Academic University of the Humanities,

Russian Federation, E-mail: yuraalexandrov@yandex.ru

A R T I C L E I N F O

Original Research

Received: December, 08.2016.

Revised: February, 20.2017.

Accepted: February, 23.2017.

doi:10.5937/IJCRSEE1701057S

UDK

37.035.6-057.875

$172.12 / .15-057.875$

\section{Keywords:}

prosocial behavior,

in-group,

out-group,

3-11-year-old children,

moral dilemmas.

\begin{abstract}
A B S T R A C T
Understanding the development of moral attitudes toward unrelated individuals from different social groups may provide insights into the role of biological and cultural factors in prosocial behavior. Children (3-11 years old, $\mathrm{N}=80$ ) were presented with moral dilemmas describing a conflict of interests between a con-specific (human) and another species (animals or aliens). Participants were asked to evaluate the behavior of a human in terms of 'good' and 'bad', and to choose whom they would help: a human aggressor who benefits at the expense of a victim in vital need, or the victim. Results showed that the older children preferred to help non-human victims significantly more often than the younger children. The evaluation of human actions was related to the proportion of such preferences. These findings are discussed from the perspectives of kin selection theory, group selection theory and the system-evolutionary approach. The implications of the study for moral education are suggested.
\end{abstract}

(C) 2017 IJCRSEE. All rights reserved.

\section{INTRODUCTION}

Prosocial behavior benefits recipients, but often costs the giver (Simpson and Willer, 2008). The emergence of prosocial behavior is described with indirect fitness benefit from the biological perspective (Hamilton, 1964), whereas the social perspective is based on continuity of consecutive stages of development (Piaget, 1997) and corresponding acquisition of social norms and rules (Kolberg, 1974; Rest et al., 2000). Firstly, both perspectives lack consistent view of altruism toward other species. The help to other species by humans

\section{Corresponding Author}

Irina M. Sozinova, M.S., Institute of Psychology Russian Academy of Science, Russian Federation E-mail: eiole@yandex.ru

\section{cc) (i) $\odot$}

This work is licensed under a Creative Commons Attribution - NonCommercial - NoDerivs 4.0. The article is published with Open Access at www.ijcrsee.com without obvious return may be an indicator of rule-guided moral behavior. Secondly, and more importantly, the biological and social considerations of the development of prosocial behavior still lack unequivocal integrity. The acquisition of moral rules can be considered within cognitive development (Kolberg, 1974, Piaget, 1997, Rest et al., 2000), whereas the prerequisites for such learning may hinge on phylogenetic adaptations, including those formed via kin or group selection (Hamilton, 1964; Wilson, 1975). Accordingly, kin-selection has been considered as an important foundation for the emergence and strengthening the 'higher levels' of cooperation in evolution (e.g. West et al., 2007a). Therefore, prosocial behavior toward related or unrelated group members may have arisen at certain consecutive stages of phylogeny.

This succession can be revealed with moral decisions concerning close or distant others (Passini, 2016). Thus, we hypothesized that an individual would support more closely 
related group members at the early stages of ontogeny (as a more basic strategy of behavior), whereas more distinguished moral rules would emerge at the later stages. In the latter case, the rules of fairness would be applied not only to relatives (in-group members), but also to members of a less related group (out-group members).

Our hypothesis has initially been built on the basic theoretical framework of the systemevolutionary theory (Shvyrkov, 1986). From this perspective, a new behavior is subserved by co-activation of systems that had emerged during episodes of learning at successive stages of ontogenesis (Quintana, 1998; Arutyunova et al., 2013). A system elaborated during learning is a set of brain and body elements activity of which provides resultative interaction with the environment (Anokhin, 1974). A new form of behavior is based on simultaneous activation of newly formed system together with successively acquired systems that constitute prior experience. Therefore, the stage-wise description of the social attitudes development may contribute to elaboration of moral education principles.

In this study we compared moral decisions of children from 3 to 11 years old. The children evaluated actions in moral dilemmas presenting a choice between helping a human who captures a desirable resource for extra benefit (labeled as an 'aggressor'), and helping someone (humans, animals, or aliens) who has already been using this resource and needs it for survival (labeled as a 'victim').

The goal of this study is to investigate the emergence of new rule-guided forms of behavior and their prerequisite adaptations. We hypothesize that the attitudes develop from helping humans (as the basic and more ancient strategy of behavior) to helping nonhumans through learning rules of fairness and justice within a culture and generalizing them to other creatures. Since these attitudes reflect corresponding moral rules, we also propose that the actions of human aggressors would be evaluated less positively by older children than by the younger children.

To our knowledge the behavior of humans who are forced to choose between an instinctive support of an in-group member and the preference based on moral rules has not been studied before. If the society invests in the deployment of the support, it is important to know what becomes of it during ontogeny. This study may also contribute to greater integration between empirical and theoretical work on altruism and prosocial behavior from the evolutionary perspective, of which there are only few examples (Leimar and Hammerstein, 2006).

\section{MATERIALS AND METHODS}

\subsection{Participants}

The participants were 80 Russian preand elementary schoolchildren (36 female), from 3 to 11 years old. We formed the following groups: 3-4 years old $(\mathrm{N}=15), 5-6$ years old $(\mathrm{N}=24), 7-9(\mathrm{~N}=24), 10-11(\mathrm{~N}=17)$ (see Table 1).

Table 1. Descriptive statistics for the age groups.

\begin{tabular}{lccccc}
\hline \multicolumn{1}{c}{ Group } & $\mathrm{N}$ & $\begin{array}{c}\text { Age } \\
\text { mean }\end{array}$ & S.D. & $\begin{array}{c}\mathrm{N} \\
\text { female }\end{array}$ & N male \\
\hline 3-4 years old & 15 & 4.33 & .44 & 7 & 8 \\
5-6 years old & 24 & 5.65 & .55 & 12 & 12 \\
7-9 years old & 24 & 8.23 & .81 & 9 & 15 \\
10-11 years old & 17 & 10.49 & .29 & 10 & 7 \\
\hline
\end{tabular}

Parents were given full information and signed informed consent regarding the research and participation of their children. All procedures performed in studies involving human participants were was approved by the Ethics Committee of Federal State-Financed Institution, Institute of psychology of Russian Academy of Science.

\subsection{Task}

Children were asked to assess moral dilemmas representing situations where a human child (in-group member) benefited from harmful actions toward other characters (outgroup members). The question was 'Who would you help?'. Helping a human child would deprive an out-group member of vital resources, whereas helping an out-group individual would deprive the human child of a benefit. The out-group characters were domestic animals (dogs), wild animals (squirrels), or aliens. An additional dilemma represented a choice between two humans. Each participant was presented with four dilemmas contrasting a victim and an aggressor. Each dilemma was illustrated with three color pictures $(90 * 85 \mathrm{~mm})$ showing the two conflicting characters and the resource. The pictures were shown along with oral presentation of the dilemmas. One of the dilemmas is given below:

There is a glade in the forest. Squirrels live in this glade. They eat and play there. 
Squirrels are very afraid of humans, so they cannot live with them. Vanya wants to build a large house in this glade for his family because he has a very large family. Currently, they live in a very small house, which is uncomfortable. If Vanya builds a large house, squirrels would not live and play in this glade, as they would have nothing to eat; however, Vanya will have a large house for his family. Who would you like to help, the squirrels, so they can stay in this glade, or Vanya, so that he can build a large house for his family?

Additionally, we presented a control dilemma with a conflict between an animal and a human where the human could be deprived of a vital resource. In the latter dilemma, all participants chose to help the human.

Two sets of dilemmas were formed to control for the order of the presentation of characters (in the example above, the victim is introduced first). The order of the dilemmas in each set was randomized. Only one set was presented to each participant. No difference of choice frequencies between the sets was found (Fisher's exact test; $p=.240$ for 'Alien' dilemma; $p=.285$ for 'Wild animal' dilemma; $p=.429$ for 'Domestic animal' dilemma; $\mathrm{p}=.594$ for 'Human' dilemma). Therefore, the results of the two sets were combined.

The goal of the study was revealed to the participants when the interviews with all of the children had been completed.

\subsection{Research design and procedure}

Children were individually interviewed at school in a separate room. First, the experimenter became acquainted with the children and asked them about their families, friends, hobbies, and so forth. Then the children were given moral dilemmas and questioned about each of them. To assess the moral evaluation of aggressor's actions in the dilemmas, the participants were presented with a 5-point Likert-type scale after each dilemma. The ratings ranged from 'very bad' to 'very good' and were labeled with smiling, sad, or neutral faces, as done elsewhere (e.g. Smetana, 1981). The interviews were audio-recorded.

For purposes beyond the scope of this article, we used a wireless device measuring heart rate in 34 participants (3-8 years old, 20 female). After moral dilemmas these participants performed other psychological tests (not related to moral development). The moral decisions were not affected by these manipulations (Fisher's exact test, $\mathrm{p}=.590$ for 'Alien dilemma'; $p=.430$ for 'Wild animal' dilem$\mathrm{ma} ; \mathrm{p}=.554$ for 'Domestic animal' dilemma; $p=.288$ for 'Human' dilemma). Therefore, both subsets of data were analyzed as a single sample.

\subsection{Measures}

Participants' choices to help a victim or to help an aggressor were coded as ' 1 ' or ' 0 ', correspondingly. The average of these (i.e. the frequency of choosing victims) served as an 'index of help' for each participant. The moral evaluations of human actions were coded from 1 ('very bad') to 5 ('very good'). Two average scores were calculated for each participant: evaluations of aggressor's action given after helping a victim were averaged separately from those after helping an aggressor. The frequencies of choices for each dilemma were compared between the groups with Fisher's exact test. The correlations between the index of help, the average evaluation ratings, and age were assessed with a non-parametric Spearman's coefficient. The differences were considered significant at $\mathrm{p}<.05$.

\section{RESULTS}

No gender differences were found in the dilemma scores or the evaluations within either groups or dilemma (dilemmas scores: Fisher's exact test, $p=.481 ; p=.158 ; p=.613$; $\mathrm{p}=.265$; evaluations of actions: Mann-Whitney test, $U=767.5, p=.946 ; U=646.5, p=.202$; $U=685, p=.345 ; U=752.5, p=.856$ for the 'Alien', 'Wild animal', 'Domestic animal', and 'Human' dilemmas, correspondingly). Therefore, the scores of boys and girls were joined together.

\subsection{Moral decisions}

The choices made by the participants in each dilemma were presented as frequencies of victim preference (Figure 1). The differences in these frequencies between the groups were revealed in all of the dilemmas, whereas the age of significant increase in preference of a victim increased as the degree of relatedness to the victim decreased - the less related the victim, the later the age of significant increase. Thus, in the 'Human' dilemma, the differences between the scores of the 3-4 and 5-6 age groups were significant (Fisher's exact test; $\mathrm{p}=.049$ ), as well as between the 3-4 and 7-9 
age groups, and the $7-9$ and $10-11$ age groups $(p=.003$ and $p=.036)$. The significant increase of victim preference occurred at a later age in the dilemmas with animals, with the differences between the scores of the 3-4 and 7-9 age groups being significant (Fisher's exact test; $\mathrm{p}=.005$ in the 'Domestic animal' dilemma, and $p=.025$ in the 'Wild animal'), along with the difference between the 3-4 and 10-11 age groups ( $\mathrm{p}=.015$ and $\mathrm{p}=.004$, correspondingly). In the 'Alien' dilemma, the difference was obtained between even more distant groups 3-4 and 10-11 ( $\mathrm{p}=.040)$, as well as between the 5-6 and $10-11(\mathrm{p}=.019)$.

Accordingly, significant differences from a random distribution (assessed with Chi-square criterion) were observed in different age groups depending on the dilemma. The distributions of decisions in ' $\mathrm{Hu}-$ man' $\left(\chi^{2}=10,67, p=0,001\right)$, 'Domestic animal' $\left(\chi^{2}=16,67, p<0,0001\right)$, and 'Wild animal' $\left(\chi^{2}=13,5, p<0,0005\right)$ dilemmas were different from random in the group of 5-6 year olds), whereas the distribution of decisions in the 'Alien' dilemma became different from random only in $10-11$ year olds $\left(\chi^{2}=7,12\right.$; $\mathrm{p}=0,008)$. However, in the 'Human' dilemma, the decrease of the victim support in the group of 10-11 year olds has lead this difference to the level of tendency $\left(\chi^{2}=2,88 ; p=0,09\right)$. No significant differences were observed in the group of 3-4 year olds.

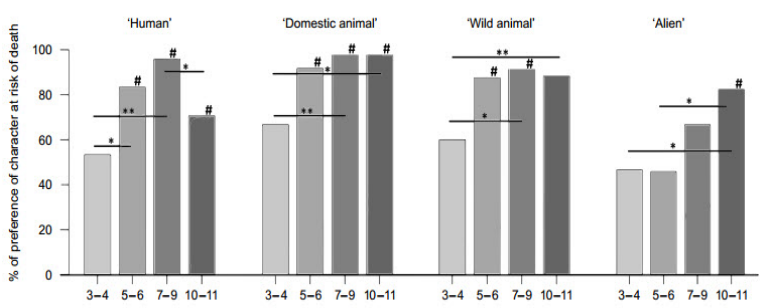

Figure 1. The frequencies of victim support in the moral dilemmas ('Human, 'Domestic animal', 'Wild animal', and 'Alien') for age groups of 3-4, 5-6, 7-9, and 10-11 years old. *Fisher's exact test, $\mathrm{p}<.05$. **Fisher's exact test, $\mathrm{p}<.01$. \# Chi-square criterion, $\mathrm{p}<0,05$.

\subsection{Evaluations of actions}

Due to technical problems, evaluations from four participants were not recorded. The remaining data had the following group content: $3-4$ years $(\mathrm{N}=15), 5-6$ years $(\mathrm{N}=23), 7-9$ years $(\mathrm{N}=22), 10-11$ years $(\mathrm{N}=16)$.

The 'index of help' was found to be positively correlated with age $(\mathrm{R}=0,46 ; \mathrm{p}<0,0001)$ and negatively correlated with the evaluations of aggressor's actions after helping a victim $(\mathrm{R}=-0,27 ; \mathrm{p}=0,016$; Figure 2$)$, but not after helping an aggressor $(\mathrm{R}=0,01 ; \mathrm{p}=0,938)$.

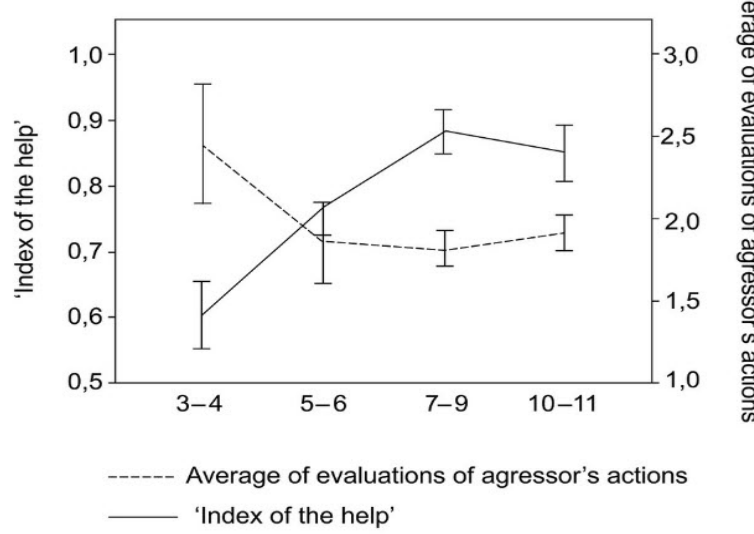

Figure 2. Decrease of average of the evaluations with increase of 'index of help' through ontogenesis. X-line: age groups 3-4 year olds; 5-6 year olds; 7-9 year olds; 10-11 year olds. Solid line shows the dynamics of 'index of help'. Dotted line shows the dynamics of the evaluations of aggressor's actions (mean values).

The evaluations of aggressor's actions after helping an aggressor were found to be negatively correlated with age on the level of tendency $(R=-0,281 ; p=0,05)$. We also found a correlation between the 'index of help' and the average evaluation rating for each group taken separately, except the group of 3-4 year olds $(\mathrm{R}=-.287 ; \mathrm{p}=.299$ for $3-4$ group; $\mathrm{R}=-.477$; $\mathrm{p}=.018$ for $5-6$ group; $\mathrm{R}=-.686 ; \mathrm{p}<.0005$ for $7-9$ group; $\mathrm{R}=-.558 ; \mathrm{p}=.020$ for $10-11$ group). Notably, children who helped out-group members tended to evaluate human actions as 'bad' or 'very bad', whereas children who helped aggressors tended to evaluate human actions as neutral — not as 'very good'.

\section{DISCUSSION}

In order to reveal the forms of behavior prerequisite for rule-guided moral judgments we contrasted four age groups with respect to moral decisions. Children aged 3-4, 5-6, 7-9, and $10-11$ years were presented with 4 moral dilemmas in which actions of a human who seeks life improvement could result in vital harm to another human, domestic animal, wild animal, or alien - i.e. creatures with different hypothetical genetic and cultural distance to human species. The participants decided whether to support an aggressor, or a victim, and evaluated the behavior of aggressors. The 
frequency of helping a victim was found to increase with age, except for the human victim, who was less supported in the group of 10-11year olds.

The preference of a non-human victim to a con-specific aggressor is considered as normative behavior, which is supported by corresponding disapproval of the aggressor's actions. Therefore, the biologically adaptive strategies of supporting in-group members may be among prerequisites of the rule-guided behavior formed during socialization. We acknowledge that the dilemmas used in this study do not fully correspond to conventional definitions of group and kin within the groupselection and kin-selection theories (West et al., 2007b). However, the interaction rate and the degree of relatedness to other creatures were central to our main propositions, like they are central to these theories. We propose that the group- and kin-selection theories describe different aspects of the same process. Kin selection theory focuses to a considerable extent on how genes influence the development of prosocial and altruistic behavior, whereas group selection theory focuses more on socio-environmental influences.

The age-related increase of the outgroup support frequencies observed here reveals specific features of socialization within culture. The trend is consistent with the suggestion of the development of moral attitudes toward out-group members in problem situations. Earlier in the ontogeny, children employ an evolutionarily more ancient behavioral strategy (helping an in-group member), whereas at later evolutionary stages, children acquire and 'internalize' (Vygotski, 1929) moral rules from their cultures (Rest et al., 2000) (in our case, they are presumably based on understanding the value of life). It has been shown that the attitudes toward in- and out-group members differ (e.g., Cunningham et al., 2004; Hein et al., 2010; Rilling et al., 2008). This difference appears early in ontogenesis - for instance, 10-month-old toddlers prefer faces of their race (Kinzler and Spelke, 2011). Presumably, attitudes toward in- and out-group members are formed via moral rules that emerged during phylogeny and can be fixed in genes and culture (House et al., 2013). The preference for unrelated group members may therefore be formed within culture early in ontogenesis but later than the preference for related group members.

The present findings may provide the initial basis for explaining kin selection as reflecting the first stage of altruism and prosocial behavior development in human phylogeny and evidence of group selection as reflecting the second stage. This suggestion is consistent with parochialism being the most ancient type of altruism, as expressed in relation to more relative group members only and associated with hostility to less relative group members (Choi and Bowles, 2007). Altruistic help is more difficult for infants to understand than empathic or instrumental help (Svetlova et al., 2010), because the former requires more cognitive complexity (see also Rest et al., 2000). Moreover, reciprocal altruism appears later in the ontogenesis than altruism toward ingroup members in animals (Reznikova, 2011). Therefore, we suppose that the reciprocal altruism (toward out-group members) is associated with the growth of intergroup interactions and the spread of cooperative actions beyond the own group.

Interestingly, the preference for alien victims in our study appears at an older age than the preference for other non-human species (10-11 years old vs. 7-9 years old). The contributing factors to this result may be the enrichment of subjective experience and a dramatic increase in the number of intergroup interaction episodes, as well as the growth of the number and heterogeneity of members of formal and natural groups in modern societies. Similar dynamics in racial attitudes was found by Quintana (Quintana, 1998). Negative attitudes toward people of other races decrease in ontogenesis. We suggest that the development of moral attitudes occurs in the direction from self and closely related individuals toward more distant and unrelated individuals: self, family, race, species, and biosphere are treated as an in-group at successive stages. These 'levels' may have individual duration or scope (see below), but follow the same order.

The evaluation of human actions differed between children making opposite decisions. Those children who helped out-group members evaluated human actions as 'bad' or 'very bad', whereas children who helped humans evaluated human actions as neutral (not as 'good' or 'very good'). We believe that these evaluations stem from children having internalized the moral rules of their cultures and realized the 'immorality', wrongness of the actions of human aggressors. However, children still want to help in-group members due to an unconscious 'relatedness'. Thus, the evaluations demonstrate that genetic and environmental factors interact in the development of altruistic behavior.

If the rule-guided support of the vic- 
tim reflects the development of the moral attitudes, then no decrease of victim support was to be expected as the age of the group increases. However, the frequency of support to a human victim in the group of 10-11-year olds was significantly lower than in the group of 7-9-year olds. This decrease was not accompanied by growth in evaluations of aggressor's actions. The oral explanations given after each choice by every participant (analysis not presented here) showed that the 10-11 year-old participants gave significantly more explanations of their choices based on rules and conventions, than participants of the other age groups. Therefore, the decrease of human victim support in the 10-11 age group was due to a more detailed knowledge of human social life, which is also a sign of socialization, but of the type beyond our empirical capacity. The in-group member preferences were evident in all groups, especially the youngest. This ancient moral attitude tempts us to speculate that moral might be under major influence of the 'genetic' factor, whereas interaction with the environment primarily defines the range of application of moral attitude. Thus, every individual expresses moral attitude, but this attitude may not involve certain groups due to specific socialization conditions (Koonz, 2003; Sozinov et al., 2015). According to our results, this range may start adhering new groups of less related creatures as early as at the age of 5-6 years. This suggests that it is important to introduce moral education in early childhood.

Using the terminology of the systemevolutionary principles that inspired our theoretical hypothesis (see Introduction), we conclude that the preference for helping related group members may have emerged within the most ancient systems of individual experience, whereas the preference for helping unrelated group members may have emerged within more recently formed systems.

We consider the results of this investigation as a necessary step to studying moral decisions under decreased social control. The victim support might be less evident, if the dilemmas were presented on an electronic device in absence of a grown-up. As a perspective for future studies, we also propose that dynamics of prosocial decisions may be characterized with intercultural differences. Given that even simple verbal discrimination task performance (Sozinov et al., 2015), as well as social (and moral) decisions in grown-ups (Arutyunova et al., 2013; Simpson and Willer, 2008) differ between cultures, the prosocial behavior may develop in culture-specific ways.

\section{CONCLUSION}

We have demonstrated that moral decisions in dilemmas confronting in- and outgroup members differ between groups of children aged 3 to 11 years old. Older children prefer helping unrelated group members more frequently than do younger children. Conventionally, the prosocial behavior may have emerged either at the earlier stages of evolution and ontogenesis, as explained by kin selection theory, or the later stages, as explained by group selection and other theories of altruism. At the same time, these two descriptions may correspond to consecutive stages of development.

\section{ACKNOWLEDGMENTS}

The research has been supported by the Russian Science Foundation under Grant [number 14-28-00229] for Institute of Psychology Russian Academy of Sciences.

\section{Conflict of interests}

The authors declare no conflict of interest.

\section{REFERENCES}

Aleksandrov, YI, \& Aleksandrova, NL (2007). Subjective experience and culture. Structure and dynamics. Social Sciences, 38(3), 109-124.

Anokhin, P. K. (1974). Biology and Neurophysiology of the Conditioned Reflex and Its Role in Adaptive Behavior: Scientific and Transl. Ed.-Samuel A. Corson. Transl. Panel-Roland Dartau, Justina Epp, Vladimir Kirilcuk. Pergamon Press.

Arutyunova, KR, Alexandrov, YI, Znakov, VV, \& Hauser, MD (2013). Moral judgments in Russian culture: Universality and cultural specificity. Journal of cognition and culture, 13(3-4), 255-285. doi:10.1163/15685373-12342094

Choi, JK, \& Bowles S. (2007). The coevolution of parochial altruism and war. Science, 318(5850), 636640. doi:10.1126/science.1144237

Cunningham, WA, Johnson, MK, Raye, CL, Gatenby, JC, Gore, JC, \& Banaji, MR (2004). Separable neural components in the processing of black and white faces. Psychological Science, 15(12), 806813. doi:10.1111/j.0956-7976.2004.00760.x

Hamilton, WD (1964). "The genetical evolution of social behaviour. I". Journal of Theoretical Biology. 7 (1), 1-16. doi:10.1016/00225193(64)90038-4

Hamilton, WD (1964). "The genetical evolution of social behaviour. II". Journal of Theoretical Biology. 7 (1), 17-52. doi:10.1016/0022- 
5193(64)90039-6

Hein, G., Silani, G., Preuschoff, K., Batson, CD, \& Singer, T. (2010). Neural responses to ingroup and outgroup members' suffering predict individual differences in costly helping. Neuron, 68(1), 149-160. doi: http://dx.doi.org/10.1016/j. neuron.2010.09.003

House, BR, Silk, JB, Henrich, J., Barrett, HC, Scelza, BA, Boyette, AH, ... \& Laurence, S. (2013). Ontogeny of prosocial behavior across diverse societies. Proceedings of the National Academy of Sciences, 110(36), 14586-14591. doi:10.1073/ pnas. 1221217110

Kinzler, KD, \& Spelke, ES (2011). Do infants show social preferences for people differing in race? Cognition, 119(1), 1-9. doi:10.1016/j.cognition.2010.10.019

Kohlberg, L. (1974). Education, moral development and faith. Journal of Moral Education, 4(1), 5-16. http://dx.doi.org/10.1080/0305724740040102

Koonz C. (2003). The Nazi Conscience. Harvard University Press. http://www.faculty.umb.edu/lawrence_blum/courses/290h_09/readings/koonz. pdf

Leimar, O., \& Hammerstein, P. (2006). Facing the facts. Journal of evolutionary biology, 19(5), 14031405. doi:10.1111/j.1420-9101.2006.01156.x

Norenzayan, A., \& Shariff, AF (2008). The origin and evolution of religious prosociality. Science, 322(5898), 58-62. doi:10.1126/science. 1158757

Passini, S. (2016). Concern for close or distant others: The distinction between moral identity and moral inclusion. Journal of Moral Education, 45(1), 74-86. http://dx.doi.org/10.1080/03057240.201 6.1156522

Piaget, J. (1997). The moral judgement of the child. Simon and Schuster. http://www.unige.ch/fapse/ files/6814/3886/5440/Article Piaget jugementmoral ENG.pdf

Quintana, SM (1998). Children's developmental understanding of ethnicity and race. Applied and Preventive Psychology, 7(1), 27-45. doi:10.1016/ S0962-1849(98)80020-6

Rest, JR, Narvaez, D., Thoma, SJ, \& Bebeau, MJ (2000). A neo-Kohlbergian approach to morality research. Journal of moral education, 29(4), 381-395. http://dx.doi.org/10.1080/713679390

Reznikova, Z. (2011). Evolutionary and Behavioural Aspects of Altruism in Animal Communities: Is There Room for Intelligence? 'Evolution'Almanac Editors Council: H. Barry III (USA), Yu. E. Berezkin (Russia), ML Butovskaya (Russia), R. Carneiro (USA), Ch. ChaseDunn (USA), VV Chernykh (Russia), HJM Claessen (Netherlands), D. Christian (Australia), S. Gavrilets (USA), AV Dybo (Russia), K. Yu. Es' kov (Russia), IV Ilvin, 122. http://www. sociostudies.org/almanac/articles/evolutionary and behavioural aspects of altruism in animal communities is there room for intelligen/

Rilling, JK, Dagenais, JE, Goldsmith, DR, Glenn, AL, \& Pagnoni, G. (2008). Social cognitive neural networks during in-group and out-group interactions. Neuroimage, 41(4), 1447-1461. http:// dx.doi.org/10.1016/j.neuroimage.2008.03.044

Simpson, B., \& Willer, R. (2008). Altruism and indirect reciprocity: The interaction of person and situation in prosocial behavior. Social Psychology Quarterly, 71(1), 37-52. doi: https://doi. org/10.1177/019027250807100106

Smetana, J. (1981). Preschool Children's Conceptions of Moral and Social Rules. Child Development, 52(4), 1333-1336. doi:10.2307/1129527

Shvyrkov, VB (1986). Behavioral specialization of neurons and the system-selection hypothesis of learning. Human memory and cognitive capabilities. Amsterdam. Elsevier, 599-611.

Sozinov, AA, Shirinkina, A., Siipo, A., Nopanen, M., Tuominen, T., Laukka, SJ, \& Alexandrov, YI (2015). The formation of encouragement achievement and loss avoidance behavior in Finnish and Russian schoolchildren. Voprosy Psihologii 4: 26-37. [In Russian]

Svetlova, M., Nichols, SR, \& Brownell, CA (2010). Toddlers' prosocial behavior: From instrumental to empathic to altruistic helping. Child development, 81(6), 1814-1827. doi:10.1111/j.14678624.2010.01512.x

Vygotski, LS (1929). II. The problem of the cultural development of the child. The pedagogical seminary and journal of genetic psychology, 36(3), 415-434. http://dx.doi.org/10.1080/08856559.1 929.10532201

West, SA, Griffin, AS, \& Gardner, A. (2007a). Evolutionary explanations for cooperation. Current Biology, 17(16), 661-672. http://dx.doi. org/10.1016/j.cub.2007.06.004

West, SA, Griffin, AS, \& Gardner, A. (2007b). Social semantics: altruism, cooperation, mutualism, strong reciprocity and group selection. Journal of evolutionary biology, 20(2), 415-432. doi: $10.1111 / \mathrm{j} .1420-9101.2006 .01258 . \mathrm{x}$

Wilson, DS (1975). A theory of group selection. Proceedings of the national academy of sciences, 72(1), 143-146. http://www.pnas.org/content/72/1/143.full.pdf

Wong, R. YM, \& Hong, YY (2005). Dynamic influences of culture on cooperation in the prisoner's dilemma. Psychological science, 16(6), 429-434. doi:10.1111/j.0956-7976.2005.01552.x 